\title{
The Key to the Solution of the World Crisis We Face
}

Human Affairs, 2021, vol. 31, issue 1

Published online: December 31, 2020 DOI: https://doi.org/10.1515/humaff-2021-0004 Nicholas Maxwell

\section{Abstract}

Humanity faces two fundamental problems of learning: learning about the universe, and learning to become civilized. We have solved the first problem, but not the second one, and that puts us in a situation of great danger. Almost all of our global problems have arisen as a result. It has become a matter of extreme urgency to solve the second problem. The key to this is to learn from our solution to the first problem how to solve the second one. This was the basic idea of the $18^{\text {th }}$ century Enlightenment, but in implementing this idea, the Enlightenment blundered. Their mistakes are still built into academia today. In order to learn how to create a civilized, enlightened world, the key thing we need to do is to cure academia of the structural blunders we have inherited from the Enlightenment. We need to bring about a revolution in science, and in academia more broadly so that the basic aim becomes wisdom, and not just knowledge.

Two problems of learning; knowledge; wisdom; the Enlightenment; reason; science; metaphysics; social inquiry; academic inquiry; global problems; civilization.

\section{The Basic Argument}

Humanity faces two absolutely fundamental problems of learning: learning about the universe and ourselves and other forms of life as a part of the universe; and learning how to create a genuinely civilized, wise world. We have solved the first problem of learning. We did that in the $17^{\text {th }}$ century when we created modern science. But we have not yet solved the second problem. That puts us in a situation of unprecedented danger. For, as a result of solving the first problem and creating modern science and technology, we have enormously increased our power to act. We have employed this vastly increased power to act to enhance human welfare in endlessly many ways, via the development of modern medicine and hygiene, modern industry and agriculture, modern transport and communications, and in countless other ways. But, in the absence of the solution to the second great problem of learning, these very successes, the outcome of our enhanced power to act have, as often as not, led to harm and death. They have led to population growth, environmental degradation, loss of wild life, mass extinction of species, gross inequality, the lethal character of modern war, the threat of nuclear weapons, pollution of earth, sea and air, and above all to the impending disasters of climate change. ${ }^{1}$ Even the pandemic of 2020 illustrates the point. Modern travel, made possible by modern science and technology, spreads the coronavirus rapidly around the world; a genuinely civilized world would be able to take swift effective action to prevent this happening, without adopting the draconian measures of China.

As a matter of extreme urgency, we need to discover how to solve the second great problem of learning. If we do not learn soon how to make progress towards a wiser, more civilized world, we may well end up destroying ourselves. But how is this to be done? Prophets and philosophers have been holding forth on the need for wisdom for millennia, without much apparent success.

This paper indicates the key to the solution to this crisis. We need to learn from our solution to the first great problem of learning how to go about solving the second great problem.

This is not an entirely new idea. It goes back to the $18^{\text {th }}$ century Enlightenment. ${ }^{2}$ A key idea of the Enlightenment, especially the French Enlightenment, was to learn from scientific progress how to make social progress towards an enlightened world. ${ }^{3}$

Unfortunately, in developing this idea, the philosophes of the Enlightenment, Voltaire, Diderot, Condorcet and the others, made three dreadful blunders. First, they failed to capture correctly the progress-achieving methods of science. Second, they then failed to generalize 
scientific method correctly so as to facilitate progress in other fields of human endeavour besides science. Third, and most disastrously, they failed to apply progress-achieving methods, generalized from science, to the social world, and above all to the task of making progress towards an enlightened world. Not only did they fail to formulate correctly progress-achieving methods, generalized from those of natural science, fruitfully applicable potentially to all worthwhile, problematic human endeavours. Far worse, they did not even conceive of the task in this methodological way. Instead, they thought the task was to develop the social sciences alongside the natural sciences. Thus the philosophes set about creating and developing the social sciences: economics, psychology, sociology, anthropology, and the rest. Instead of attempting to apply reason, extracted from science, to the task of making progress towards an enlightened world, the philosophes sought merely to make progress in knowledge about the social world. They thought that such knowledge had to be acquired as an essential preliminary to the task of making social progress towards enlightenment or civilization.

This botched version of the profound, basic Enlightenment idea was then developed throughout the $19^{\text {th }}$ century by J.S. Mill, Karl Marx, Max Weber and others, and built into academia in the early $20^{\text {th }}$ century with the creation of academic social science: economics, anthropology, sociology and the rest. ${ }^{4}$ As a result, modern science, and modern academic inquiry more generally, still embody the three ancient blunders of the $18^{\text {th }}$ century Enlightenment. Academic inquiry as it exists today is the outcome of an attempt to put the profound, basic Enlightenment idea into practice - the idea of learning from our solution to the first great problem of learning how to solve the second one. Unfortunately it is a very seriously botched attempt. As a consequence, academia today does not, as it should, actively seek to help humanity solve those problems of living, including global problems, that need to be solved if humanity is to make progress towards a better, wiser, more civilized and enlightened world. Instead, it devotes itself to acquiring knowledge - knowledge of the natural world, and knowledge of the social world. Judged from the standpoint of helping humanity learn how to create a better world, academic inquiry, devoted primarily to the pursuit of knowledge, is damagingly irrational in a wholesale, structural way, and this irrationality of our institutions of learning has much to do with the dangerous situation we find ourselves in today. We fail to learn how to make progress towards a better world because our institutions of learning are profoundly dysfunctional intellectually. They have in them three structural blunders inherited from the Enlightenment. ${ }^{5}$

It is these three blunders that we need to put right to develop a kind of academic inquiry rationally devoted to helping humanity make progress towards as good, civilized and wise a world as possible. First, we need to adopt and implement a new conception of science that acknowledges profoundly problematic metaphysical, value and political assumptions inherent in the aims of science and, as a result, adopts a meta-methodology designed to facilitate improvement of aims as science proceeds. Second, this aims-improving, progress-achieving conception of scientific method needs to be generalized to form a new, aims-improving, progress-achieving conception of rationality, fruitfully applicable, potentially, to all worthwhile endeavours with problematic aims. And third, social inquiry and the humanities need to be transformed so that they take up the task of helping humanity get this new conception of rationality into the fabric of social life, into all our other human endeavours besides science: politics, industry, agriculture, economics, the media, the law, finance, international affairs. As a result, humanity would have what it so urgently needs, a kind of academic enterprise rationally devoted to helping us make social progress towards a genuinely civilized, wise, enlightened world - a world that has the capacity to discover undesirable consequences of new actions made possible by new technology, and then modify actions before their undesirable consequences become too widespread.

\section{From Knowledge-Inquiry to Wisdom-Inquiry}


There are two conceptions, and kinds, of academic inquiry that we need to consider: knowledge-inquiry and wisdom-inquiry.

Knowledge-inquiry is what, by and large, we have today. It has the three blunders of the Enlightenment built into it. The basic intellectual aim is to acquire knowledge; the basic social aim to help promote human welfare by means of the application of knowledge, technological know-how and expertise. First, knowledge is to be acquired; once acquired, it can be applied to help promote human welfare. Values, politics, policies, problems of living and their proposed solutions must all be excluded from the intellectual domain of inquiry, to preserve its objectivity and intellectual integrity (although factual claims about these things can be included). According to this view, paradoxically, human values must be excluded from the intellectual domain so that authentic factual knowledge may be produced, and academic inquiry may be of genuine human value, and not degenerate into mere propaganda and ideology. ${ }^{6}$

At the core of knowledge-inquiry there is a philosophy of science, standard empiricism, taken for granted by the scientific community today, even though violated in scientific practice. This holds that evidence decides what is to be accepted in science. The simplicity, unity or explanatory character of a theory may influence what is accepted as well, but not in such a way that the world itself is presupposed to be simple, unified or comprehensible. A key tenet of standard empiricism is that no thesis about the world can be accepted as a part of scientific knowledge independently of evidence.

Judged from the standpoint of improving our solution to the first great problem of learning, knowledge-inquiry seems astonishingly successful. But judged from the standpoint of improving our solution to the second great problem of learning - learning to acquire global civilization or enlightenment - knowledge-inquiry is an intellectual and humanitarian disaster. Indeed, in enhancing knowledge and technological know-how and at the same time failing to improve our solution to the second great problem of learning, knowledge-inquiry in effect intensifies the world crisis that we face for, as I indicated above, that crisis stems from solving the first problem of learning and failing to solve the second one.

Wisdom-inquiry is what emerges when knowledge-inquiry is modified just sufficiently to eliminate the three great Enlightenment blunders inherent in its structure, and thus cure it of its gross, wholesale irrationality. Wisdom-inquiry is rationally designed and devoted to improving our solutions to both great problems of learning. It has, as its basic intellectualsocial aim, to seek and promote wisdom, understood to be the capacity, active endeavour and desire to realize what is of value in life, for oneself and others, wisdom thus including knowledge, technological know-how and understanding, but much else besides. ${ }^{7}$

Even though knowledge-inquiry is an intellectual and humanitarian disaster judged from the standpoint of helping humanity make progress towards an enlightened world, nevertheless, paradoxically, it has been developed with precisely that task in mind.

Knowledge-inquiry is intended to help us learn how to make progress towards an enlightened world; it fails because the design is lousy - the outcome of the three great blunders of the Enlightenment.

This point is of profound significance. It means that, in order to create a kind of academic inquiry that helps us, effectively, solve both great problems of learning, we do not have to fumble in the dark, guessing at what may be required. There are clear instructions before us. We need to get clear about what, precisely, the blunders of the Enlightenment are, what the structural intellectual flaws of knowledge-inquiry are, and then modify knowledge-inquiry just sufficiently to remove these flaws we have inherited from the $18^{\text {th }}$ century Enlightenment.

I now indicate what is wrong, and what needs to be done to put matters right. There are two arguments: the first appeals to a "problem solving" conception of rationality, the second to an "aim improving" conception, arrived at by generalizing the aim improving conception of scientific method that needs to replace standard empiricism. 


\section{First Argument: Problem Solving Rationality}

Judged from the standpoint of helping us solve the second great problem of learning - or merely from the standpoint of helping to promote human welfare - knowledge-inquiry violates in a structural way THREE of the four most elementary rules of rational problem solving conceivable. These four rules are:-

(1) Articulate, and improve the articulating of, the problem to be solved.

(2) Propose and critically assess possible solutions.

(3) When confronted by a recalcitrant problem, break it up into specialized, preliminary problems.

(4) Interconnect fundamental and specialized problem solving, so that each influences the other. ${ }^{8}$

Granted that academia seeks to help promote human welfare or, more ambitiously, help us make progress towards as good and enlightened a world as possible, the problems it seeks to solve are, fundamentally, problems of living - problems of suffering, injustice, poverty. These are solved by what we $d o$, or refrain from doing. Even when knowledge or

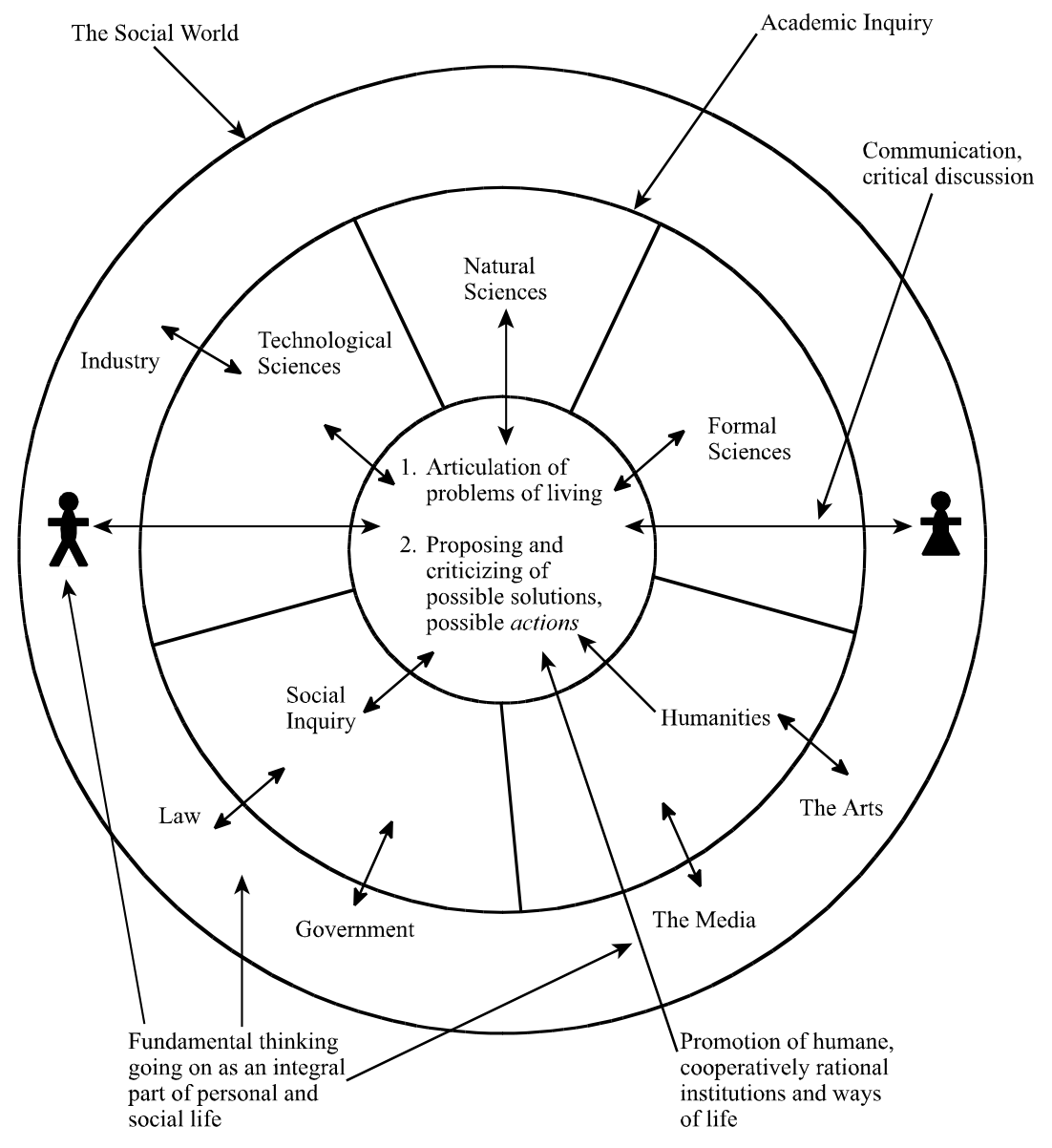

Figure 1: Wisdom-Inquiry Implementing Problem-Solving Rationality

technology is important, as it is in medicine for example, or agriculture, it is always what this knowledge enables us to do that solves the problem of living, not the knowledge as such. Thus, in order to pursue the goal of promoting human welfare in such a way that elementary rules of rational problem solving are complied with, academia must:

(1) Articulate, and improve the articulating of, problems of living. 
(2) Propose and critically assess possible solutions - possible actions, policies, political programmes, ways of living, philosophies of life.

(3) When confronted by recalcitrant problems of living, break them up into specialized, preliminary problems of knowledge and technological know-how.

(4) Interconnect fundamental and specialized problem solving, so that each influences the other.

Academia as it exists today, massively influenced by knowledge-inquiry, ${ }^{9}$ puts rule (3) into effect brilliantly. This is the most striking feature of the modern academic enterprise: its maze of specialized disciplines. But disastrously, it fails to put rules (1), (2) and (4) into practice. THREE of the four most elementary rules of rational problem solving are violated. And this violation of reason results in academia failing to do what most needs to be done to help promote human welfare: articulate problems of living, and propose and critical assess possible actions designed to solve them. Academia does not even entertain the idea that it has, as an absolutely vital task, to promote rational tackling of problems of living in the social world. Not only does academia fail to promote vital public education about what our grave global problems are, and what we need to do about them; it does not even take such vital public education to be a proper, basic task of academia at all. Take the climate crisis. Extinction Rebellion and Greta Thunberg have done more in one year to bring the crisis to public attention than all the universities of the world have done in 60 years - ever since we first knew about climate change. Academia, as a result of implementing knowledge-inquiry, betrays reason, and as a result betrays humanity.

In order to cure academia of this gross and profoundly damaging structural irrationality, and thus create a first, rough version of wisdom-inquiry, we need to modify knowledge-inquiry just enough to ensure that all four rules of rational problem solving are put into practice, in the way just indicated. That requires that we make the following structural changes to academia. The social sciences need to be transformed so that they cease to be sciences, or even disciplines devoted primarily to the pursuit of knowledge, and become instead enterprises that seek to promote increasingly cooperatively rational resolving of conflicts and problems of living in the social world. Insofar as social inquiry seeks knowledge, it is to improve knowledge about what our problems of living are, and how good proposals for action are from the standpoint of helping us solve our problems of living, and realize what is of value in life. Social inquiry, so transformed, becomes intellectually more fundamental than natural science in that social inquiry and the humanities seek to help humanity solve its fundamental problems - those problems of living we need to solve to realize what is of value in life (and thus, ultimately, make progress towards as good a world as possible). The relationship between academia and the social world needs to be transformed, so that academia actively promotes public education about what our problems are, and what we need to do about them, by means of discussion and debate - ideas, achievements, experiences, proposals and arguments going in both directions. Academia needs to become a people's civil service, doing openly for the public what actual civil services are supposed to do in secret for governments. It needs to be recognized that the most important and fundamental inquiry going on in the world is not academic inquiry, but rather the inquiry people engage in, influencing their actions, as they seek to realize what is of value (as best they can) in life. Academic inquiry is a specialized component of personal and social inquiry; it has, as a basic task, to help personal and social life inquiry to flourish: see Figure 1.

\section{Second Argument: Aim-Oriented Rationality}

I now spell out, in a little more detail than in section 1, the three Enlightenment blunders inherent in academia today, and what needs to be done to remove them, thus transforming knowledge-inquiry into wisdom-inquiry. This argument builds on and develops the argument of the previous section. It results in a version of wisdom-inquiry that improves on the version depicted in Figure 1. 
The first blunder concerns the precise nature of the progress-achieving methods of natural science. The scientific community today takes standard empiricism (SE) uncritically for granted, ${ }^{10}$ just as the philosophes did in the $18^{\text {th }}$ century. ${ }^{11}$ (SE is defined in section 2. )

But SE is untenable. ${ }^{12}$ Science does not, and cannot, proceed in accordance with the edicts of SE. Theoretical physics only ever accepts unified theories, even though endlessly many disunified rivals are always available that fit the evidence even better. In persistently ignoring these endlessly many empirically more successful, disunified theories, physics thereby makes a big implicit, metaphysical ${ }^{13}$ assumption about the nature of the universe: it is such that all disunified theories are false. There is, in other words, some kind of unified pattern of physical law that runs through all physical phenomena. The universe is such that there is a yet-to-be-discovered physical "theory of everything" that is unified, true, and in principle predicts and explains all physical phenomena. This metaphysical thesis (asserting that the universe is physically comprehensible) is implicit in the methods of physics, those methods that demand that a theory, in order to be acceptable, must be unified. (A physical theory is disunified to degree $\mathrm{N}$ if what it asserts about the phenomena divides into $\mathrm{N}$ distinct domains such that what is asserted within any domain is the same throughout that domain, but different from what is asserted in all the other domains. The theory is unified if $\mathrm{N}=1$. $)^{14}$

In short, in accepting unified theories only, and persistently ignoring endlessly many empirically more successful, disunified rivals, physics thereby makes a permanent, implicit, metaphysical assumption about the nature of the universe: it is such that all disunified theories are false. That suffices to refute SE (since SE holds that no assumption about the world can be a part of scientific knowledge independent of evidence).

In order to correct the first big blunder we have inherited from the $18^{\text {th }}$ century Enlightenment, still built into academia today, we need to adopt and put into practice a new conception of science that explicitly acknowledges, as a part of scientific knowledge, that which standard empiricism denies: the substantial, highly influential and problematic metaphysical assumption that there is some kind of underlying unity inherent in the universe, all disunified theories being false.

We do not, however, know that the universe is physically comprehensible. It is a conjecture. Much less do we know to be true the much more specific version of this metaphysical thesis, accepted implicitly by physics at any stage in its development. A glance at the past reveals that physics has changed a number of times its more or less specific view as to how the universe is physically comprehensible. Granted that it is almost inevitable that the specific conjecture that is adopted (implicitly) by physics at any stage in its development will be false, the all-important question becomes: How can we best improve the thesis that is adopted?

The solution to this problem is to adopt a view I call aim-oriented empiricism: see figure 2. Aim-oriented empiricism (AOE) represents the currently implicit assumption of physics in the form of a hierarchy of assumptions. As we go up the hierarchy, metaphysical assumptions become less and less substantial and thus more and more likely to be true, and also such that their truth becomes more nearly required for science, or the pursuit of knowledge, to be possible at all. Assumptions high up in the hierarchy, and associated methods, provide a relativity secure, stable framework within much more substantial and insecure assumptions, and associated methods, low down in the hierarchy, can be developed, assessed, and improved. Those "low down" assumptions are accepted which (a) best accord with the accepted assumption above in the hierarchy, and (2) are associated with the most empirically progressive research programme of physics. The meta-methodology of AOE makes it possible for physics to improve its assumptions and associated methods as it proceeds in the light of which best promote scientific knowledge. As science improves its knowledge about the nature of the universe, it improves its methods, its knowledge about how to improve knowledge - a sort of positive feedback process which actually goes on in physics to some extent beneath the smokescreen of SE, and which helps explain the explosive growth in scientific knowledge. 
Not only does AOE facilitate improvement of assumptions implicit in the methods of physics, in the light of which best promote scientific progress; in addition, AOE provides the solution to Hume's problem of induction. ${ }^{15}$ As I have shown elsewhere in detail, AOE exhibits science as a rational enterprise, ${ }^{16}$ and provides theoretical physics with a rational, if fallible, method of discovery ${ }^{17}$ - striking achievements wholly beyond SE. ${ }^{18}$

All this may be reformulated in terms of aims. SE holds that the intellectual aim of physics is truth. But that conceals the real and highly problematic aim of physics of discovering, not truth per se, but rather truth presupposed to be unified or explanatory, explanatory truth as it may be called. This aim, precisely because it is profoundly problematic, must be improved as physics proceeds. AOE, in representing this aim as a hierarchy of aims that become less and less specific and problematic as one goes up the hierarchy, provides a meta-methodological framework for improving the problematic aims of physics - specifically those low down in the hierarchy - as physics proceeds. The aim and methods physics improve as physics proceeds, and theoretical knowledge and understanding in physics improve.

AOE needs to be adopted and implemented, not just in physics, but throughout the natural sciences. All natural sciences have problematic aims, in part because there are problematic factual assumptions inherent in them, in part because there are problematic assumptions

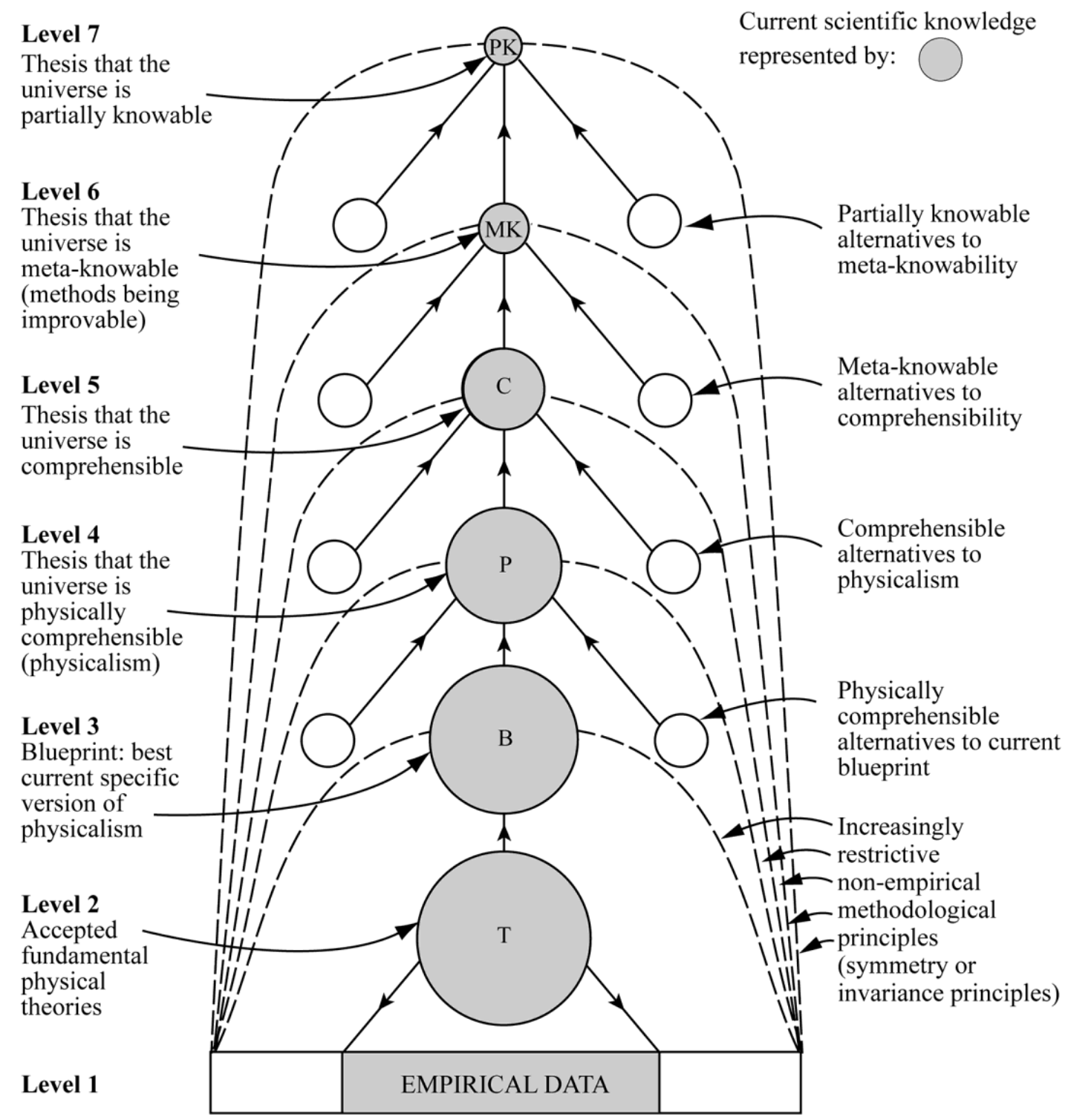

Figure 2: Aim-Oriented Empiricism 
concerning values and social use, or politics, inherent in them. Science, quite properly seeks, not truth as such, but rather truth that is of value - truth that is of intrinsic interest, or of social use. But of value or use to whom? And in what way? The ideal aim for any science is that which (a) it is possible to discover, and the same time (b) it is of value to discover. It will often be highly problematic to discover that aim which has both features, (a) and (b).

According to SE, the intellectual content of science is, crudely speaking, made up of two domains: (1) evidence, and (2) theory. According to AOE, our whole conception of science needs to be transformed so that its intellectual content is made of three domains: (1) evidence, (2) theory, and (3) aims. Sustained discussion of problems associated with (3) is just as important as discussion of problems associated with (2) and (1). Journals need to be devoted to (3); Nobel prizes may be won as a result of contributions to (3).

Once the scientific community has brought about the scientific revolution involved in rejecting SE, and adopting and implementing in scientific practice AOE instead, the first blunder of the Enlightenment will have been corrected.

The second Enlightenment blunder has to do with how scientific method is to be generalized to become fruitfully applicable, potentially, to all that we do. Having failed to grasp the progress-achieving methods of science accurately, the philosophes of the Enlightenment naturally failed to generalize these methods correctly, to form a conception of rationality capable of providing us with the greatest possible help with solving our problems, realizing our aims, whatever we may be doing. SE holds that science has a fixed intellectual aim: truth. Conceptions of rationality, arrived at by generalizing SE, have this feature too; they are about means, and not about improvement of aims or ends. And still, today, conceptions of reason are about means, and not about the improvement of ends.

Crucially, it is not just in science that aims are profoundly problematic; this is the case in life too. ${ }^{19}$ All too often, in personal, social and institutional life, basic aims are profoundly problematic, either because they are unrealizable, or because they have all sorts of unforeseen, undesirable consequences. Many of our current global problems have arisen because, thanks to modern science and technology, we have achieved astonishing success in the pursuit of goals that may, initially, seem highly desirable but which subsequently turn out to have all sorts of undesirable consequences. ${ }^{20}$ We pursue health employing modern hygiene and medicine, and create a population explosion; we develop modern agriculture, and destroy the environment and devastate wild life; we deploy antibiotics, and generate drug resistance; we create the internet, and facilitate crime and undermine democracy; we industrialize, and create the climate crisis. We need a conception of rationality which helps us improve problematic aims as we act. Standard empiricism, with its fixed aim for science, cannot provide this, but AOE can.

Thus, in order to execute the second step of the Enlightenment programme properly, it is essential to take AOE as the correct characterization of the progress-achieving methods of science, and generalize this to form a new conception of rationality - aim-oriented rationality - that facilitates the improvement of problematic aims as we act. According to aim-oriented rationality (AOR), we need to represent problematic aims in the form of a hierarchy, aims becoming increasingly unspecific and unproblematic as we ascend the hierarchy. As a result, we create a framework of relatively unproblematic aims, and associated methods, high up in the hierarchy, within which much more specific and problematic aims, and associated methods, low down in the hierarchy, can be improved as we act. ${ }^{21}$ Aims and methods are improved in the light of what we experience, what we enjoy and suffer, what we learn, as a result of our actions, and in the light of aims and methods higher up in the hierarchy: see figure 3 .

AOR provides a meta-methodological framework for the improvement of ideas for action, and of action itself, in the light of what we experience when actions are performed, or what we imagine we would experience if ideas for action were to be performed. In providing the means to improve our aims as we act, it facilitates realization of what is of value in life. 


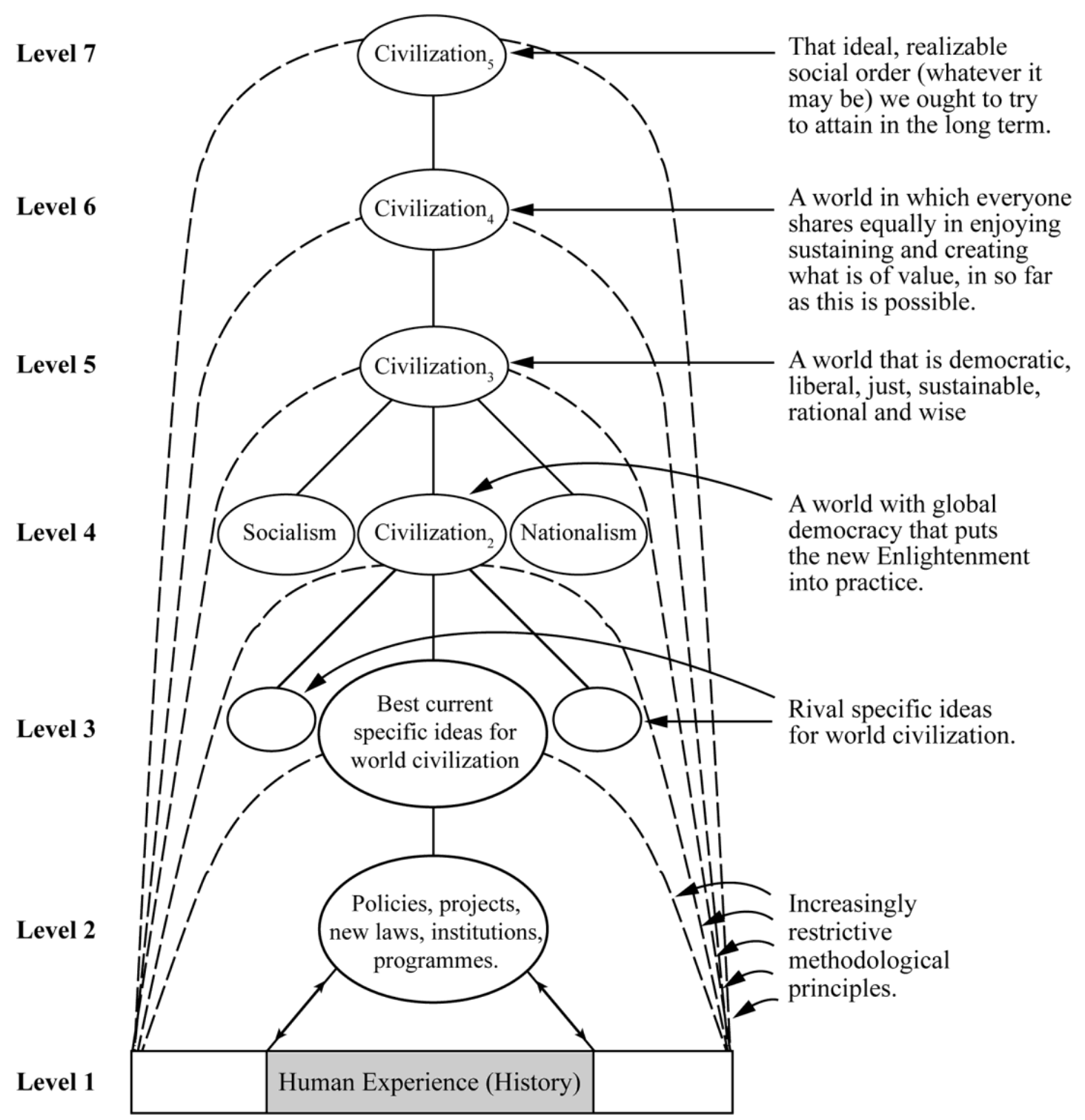

\section{Figure 3: Aim-Oriented Rationality (AOR) Applied to the Task of Making Progress Towards an Enlightened, Civilized World}

Feelings and desires are vital aspects of AOR. We cannot hope to discover for ourselves what is of value in life, what aims we should pursue, if we do not attend to our feelings and desires; but not everything that feels good is good, and not everything we desire is desirable. AOR puts desire and intellect in touch with one another, so that each may learn from the other. AOR heals the gulf between traditional rationalism and romanticism, and massively improves on both - a point to be developed below.

The third Enlightenment blunder, still built into academia today, is by far the worst, the most damaging. Progress-achieving rationality is not applied directly to social life to help solve global problems and achieve social progress towards as good and enlightened a world as possible. Instead, it is applied to social science, to the task, merely, of making progress in knowledge of social phenomena. It is this monumental blunder, developed throughout the $19^{\text {th }}$ and early $20^{\text {th }}$ century, that is responsible for the creation of what we have today, academia shaped by knowledge-inquiry.

In order to correct this third, and most disastrous blunder, the social sciences and humanities need to be radically transformed so that their fundamental task becomes to help get into the fabric of personal, social, institutional and cultural life the progress-achieving methods of AOR, so that progress may be made towards as good a world as possible. As I 
have already stressed, social inquiry is not science; it is not even, primarily, devoted to the pursuit of knowledge. Rather, social inquiry is social methodology or social philosophy. Government, politics, industry, finance, the law, agriculture, economics, education, the media: the basic task of social inquiry is to help all these institutions and social endeavours put AOR into practice, so that problematic aims may be improved as we live, and we may make social progress towards a better world in something like the way natural science makes progress in knowledge. In some cases legislation may be required to ensure AOR is implemented. Insofar as social inquiry seeks knowledge, it is to improve knowledge about what our problems of living are, what problems there are associated with our aims, and how good proposed actions are in helping us to achieve genuinely desirable social goals if they were to be put into practice.

Almost all our distinctively $21^{\text {st }}$ century global problems have arisen because we have failed to put AOR into practice in our political, economic, industrial, international life. We have failed to anticipate undesirable consequences of major new social endeavours, made possible by science and technology or, when such anticipations have been made, we have failed to act - to modify what we do - so as to avoid experiencing these undesirable consequences. We have failed to develop the social-political-economic muscle needed to perform such actions. We develop modern hygiene and medicine around the world but fail to make birth control freely available universally, to check rising populations. We develop agriculture but fail to modify how it develops when it becomes apparent we are destroying natural habitats, destroying wild life, and causing mass extinctions. We develop modern industry, power-production and transport, but fail to respond adequately when we discover we are transforming our climate so that densely inhabited regions of the earth may become uninhabitable, mass migration will ensue, with wars a likely outcome. We develop nuclear weapons to increase our security, when in fact the mere existence of such weapons, ready for launching at the touch of a button, threatens the future of humanity. It is not just that we have failed to put AOE into social practice. We have not even conceived of the need to do so. Academia fails to help humanity learn how to do it, and even worse, does not even conceive it to be a basic task it should try to perform. No wonder the world is in a state of crisis.

In order to implement wisdom-inquiry, academia must strive to help humanity put AOR into social practice: figure 3 depicts AOR applied to the endeavour to make progress towards a civilised world. But academia must also strive itself to put AOR into practice, so that it may teach by example, academia becoming as perfect an example as possible of what AOR can be. ${ }^{22}$

One outcome of getting AOR into social and institutional life is that it becomes possible for us to develop and assess rival philosophies of life as a part of social life, somewhat as theories are developed and assessed within science. The hierarchical methodology of AOR provides a framework within which competing views about what our aims and methods in life should be - competing religious, political and moral views - may be cooperatively assessed and tested against broadly agreed, unspecific aims (high up in the hierarchy of aims) and the experience of personal and social life. There is the possibility of cooperatively and progressively improving such philosophies of life (views about what is of value in life and how it is to be achieved), much as theories are cooperatively and progressively improved in science. In science, ideally, theories are critically assessed with respect to each other, with respect to metaphysical ideas concerning the comprehensibility of the universe, and with respect to experience (observational and experimental results). In a somewhat analogous way, diverse philosophies of life may be critically assessed with respect to each other, with respect to relatively uncontroversial, agreed ideas about aims and what is of value, and with respect to experience - what we do, achieve, fail to achieve, enjoy and suffer as a result of implementing the philosophy of life in question - the aim being to improve philosophies of life (and more specific philosophies of more specific enterprises within life such as government, education or art) so that they offer greater help with the realization of what is of value in life. AOR is, in other words, a kind of empiricism. It differs from empiricism in science, however, in that actions, policies and 
philosophies of life are assessed, not theories; and "experience" is what we enjoy and suffer as a result of implementing policies, and not merely observation and experiment (as in science).

AOR is especially relevant to the task of resolving conflicts about aims and ideals, as it helps disentangle agreement (high up in the hierarchy) and disagreement (more likely to be low down in the hierarchy).

Wisdom-inquiry, because of its greater rigour, has intellectual standards that are, in important respects, different from those of knowledge-inquiry. Whereas knowledge-inquiry demands that emotions and desires, values, human ideals and aspirations, philosophies of life be excluded from the intellectual domain of inquiry, wisdom-inquiry requires that they be included. In order to discover what is of value in life, it is essential that we attend to our feelings and desires. But not everything we desire is desirable, and not everything that feels good is good. Feelings, desires, and values need to be subjected to critical scrutiny. And of course feelings, desires and values must not be permitted to influence judgements of factual truth and falsity. Wisdom-inquiry embodies a synthesis of traditional rationalism and romanticism. It includes elements from both, and it improves on both. It incorporates romantic ideals of integrity, having to do with motivational and emotional honesty, honesty about desires and aims; and at the same time, it incorporates traditional rationalist ideals of integrity, having to do with respect for objective fact, knowledge, and valid argument. Traditional rationalism takes its inspiration from science and method; romanticism takes its inspiration from art, from imagination, and from passion. Wisdom-inquiry holds art to have a fundamental rational role in inquiry, in revealing what is of value, and unmasking false values; but science, too, is of fundamental importance. What we need, for wisdom, is an interplay of sceptical rationality and emotion, an interplay of mind and heart, so that we may develop mindful hearts and heartfelt minds. ${ }^{23}$ It is time we healed the great rift in our culture, so graphically depicted by C.P. Snow. ${ }^{24}$

Wisdom-inquiry does not just do better justice to the social or practical dimension of inquiry than knowledge-inquiry; it does better justice to the "intellectual" or "cultural" aspects as well.

From the standpoint of the intellectual or cultural aspect of inquiry, what really matters is the desire that people have to see, to know, to understand, the passionate curiosity that individuals have about aspects of the world, and the knowledge and understanding that people acquire and share as a result of actively following up their curiosity. An important task for academic thought in universities is to encourage non-professional thought to flourish outside universities. As Einstein once remarked, "Knowledge exists in two forms - lifeless, stored in books, and alive in the consciousness of men. The second form of existence is after all the essential one; the first, indispensable as it may be, occupies only an inferior position." 25

Wisdom-inquiry is designed to promote passionate curiosity in a number of ways. It does so as a result of holding thought, at its most fundamental, to be the personal thinking we engage in as we live. It does so by recognizing that acquiring knowledge and understanding involves articulating and solving personal problems that one encounters in seeking to know and understand. It does so by recognizing that passion, emotion and desire, have a rational role to play in inquiry, disinterested research being a myth. Again, as Einstein has put it "The most beautiful experience we can have is the mysterious. It is the fundamental emotion which stands at the cradle of true art and true science. Whoever does not know it and can no longer wonder, no longer marvel, is as good as dead, and his eyes are dimmed." 26

Knowledge-inquiry, by contrast, all too often fails to nourish "the holy curiosity of inquiry", ${ }^{27}$ and may even crush it out altogether. Knowledge-inquiry gives no rational role to emotion and desire; passionate curiosity, a sense of mystery, of wonder, have no place, officially, within the rational pursuit of knowledge. The intellectual domain becomes impersonal and split off from personal feelings and desires; it is difficult for "holy curiosity" to flourish in such circumstances. Knowledge-inquiry hardly encourages the view that inquiry at its most fundamental is the thinking that goes on as a part of life; on the contrary, it 
upholds the idea that fundamental research is highly esoteric, conducted by physicists in contexts remote from ordinary life. Even though the aim of inquiry may, officially, be human knowledge, the personal and social dimension of this is all too easily lost sight of, and progress in knowledge is conceived of in impersonal terms, stored lifelessly in books and journals. Rare is it for popular books on science to take seriously the task of exploring the fundamental problems of a science in as accessible, non-technical and intellectually responsible a way as possible. ${ }^{28}$ Such work is not highly regarded by knowledge-inquiry, as it does not contribute to "expert knowledge". The failure of knowledge-inquiry to take seriously the highly problematic nature of the aims of inquiry leads to insensitivity as to what aims are being pursued, to a kind of institutional hypocrisy. Officially, knowledge is being sought "for its own sake", but actually the goal may be immortality, fame, the flourishing of one's career or research group, as the existence of bitter priority disputes in science indicates. Education suffers. Science students are taught a mass of established scientific knowledge but may not be informed of the problems which gave rise to this knowledge, the problems which scientists grappled with in creating the knowledge. Even more rarely are students encouraged themselves to grapple with such problems. And rare, too, is it for students to be encouraged to articulate their own problems of understanding that must, inevitably, arise in absorbing all this information, or to articulate their instinctive criticisms of the received body of knowledge. All this tends to reduce education to a kind of intellectual indoctrination and serves to kill "holy curiosity". ${ }^{29}$ Officially, courses in universities divide up into those that are vocational, like engineering, medicine and law, and those that are purely educational, like physics, philosophy or history. What is not noticed, again through insensitivity to problematic aims, is that the supposedly purely educational are actually vocational as well: the student is being trained to be an academic physicist, philosopher or historian, even though only a minute percentage of the students will go on to become academics. Real education, which must be open-ended, and without any pre-determined goal, rarely exists in universities, and yet few people notice. ${ }^{30}$

In order to enhance our understanding of persons as beings of value, potentially and actually, we need to understand them empathetically, by putting ourselves imaginatively into their shoes, and experiencing, in imagination, what they feel, think, desire, fear, plan, see, love and hate. For wisdom-inquiry, this kind of empathic understanding is rational and intellectually fundamental. Articulating problems of living, and proposing and assessing possible solutions is, we have seen, the fundamental intellectual activity of wisdom-inquiry. But it is just this that we need to do to acquire empathic understanding. Social inquiry, in tackling problems of living, is also promoting empathic understanding of people. Empathic understanding is essential to wisdom. Elsewhere I have argued, indeed, that empathic understanding plays an essential role in the evolution of consciousness. It is required for cooperative action, and even for science. ${ }^{31}$

Granted knowledge-inquiry, however, empathic understanding hardly satisfies basic requirements for being an intellectually legitimate kind of explanation and understanding It has the status merely of "folk psychology", on a par with "folk physics." 32

Wisdom-inquiry is both more rigorous, and better able to serve the best interests of humanity, than knowledge-inquiry. It does better justice to both aspects of inquiry: the intellectual or cultural aspect, and the humanitarian or practical aspect. We urgently need to bring about an intellectual/institutional revolution in academia in universities around the world..$^{33}$ We need a change of paradigm in the whole conception of what constitutes intellectually worthwhile inquiry devoted to the best interests of humanity. We need to put wisdom-inquiry into academic practice so that we may come to solve both fundamental problems of learning: learning about the universe, and learning to create a genuinely civilized, enlightened world.

\section{References}

Einstein, A., 1949, "Autobiographical Notes", in P. A. Schilpp, ed. Albert Einstein: 
Philosopher-Scientist, Open Court, Illinois, pp. 3-94. , 1973, Ideas and Opinions, Souvenir Press, London.

Farganis, J., ed., 1993, Readings in Social Theory: The Classic Tradition to Post-Modernism, Introduction, McGraw-Hill, New York.

Gay, P., 1973, The Enlightenment: An Interpretation, Wildwood House, London.

Hayek, F.A., 1979, The Counter-Revolution of Science, LibertyPress, Indianapolis.

Israel, J.I., 2013, Democratic Enlightenment, Oxford University Press, Oxford.

Maxwell, N., 1974, The Rationality of Scientific Discovery, Part I: The Traditional

Rationality Problem, Philosophy of Science 41, pp. 123-53.

, 1976, What's Wrong With Science?, Bran's Head, Hayes.

, 1979, Induction, Simplicity and Scientific Progress, Scientia 114, 1979, pp. 629-

53.

1980, Science, Reason, Knowledge and Wisdom: A Critique of Specialism, Inquiry 23, pp. 19-81.

1984. From Knowledge to Wisdom: A Revolution in the Aims and Methods of

Science, Blackwell, Oxford.

1992. What kind of inquiry can best help us create a good world? Science,

Technology and Human Values 17, 205-27.

1993, Induction and Scientific Realism: Einstein versus van Fraassen, British

Journal for the Philosophy of Science 44, pp. 61-79, 81-101 and 275-305.

1997, Must Science Make Cosmological Assumptions if it is to be Rational?, in The

Philosophy of Science: Proceedings of the Irish Philosophical Society Spring

Conference, edited by T. Kelly, Irish Philosophical Society, Maynooth, 1997, pp. 98-146.

1998, The Comprehensibility of the Universe: A New Conception of Science,

Oxford University Press, Oxford.

, 1999, Has Science Established that the Universe is Comprehensible?, Cogito 13,

pp. 139-145.

2000a, A new conception of science, Physics World 13, No. 8, 2000, pp. 17-18.

, 2000b, Can Humanity Learn to become Civilized? The Crisis of Science without

Civilization, Journal of Applied Philosophy 17, 2000, pp. 29-44.

2001, The Human World in the Physical Universe: Consciousness, Free Will and

Evolution, Rowman and Littlefield, Lanham, Maryland, Appendix 3.

2002a, Is Science Neurotic? Metaphilosophy 33, no. 3, April 2002, pp. 259-299.

2002b, The Need for a Revolution in the Philosophy of Science, Journal for

General Philosophy of Science 33, 2002, pp. 381-408. Number 2.

2004, Is Science Neurotic?, London: World Scientific.

2006, Practical Certainty and Cosmological Conjectures, in Is there Certain

Knowledge?, ed. Michael Rahnfeld, Leipziger Universitätsverlag, Leibzig, 2006, pp. 44-59.

2007, From Knowledge to Wisdom: A Revolution for Science and the Humanities,

Pentire Press, London (2nd extended ed. of Maxwell, 1984).

2009, Muller's Critique of the Argument for Aim-Oriented Empiricism, Journal for

General Philosophy of Science, vol. 40, 2009, pp. 103-114.

,2010, Cutting God in Half - And Putting the Pieces Together Again: A New

Approach to Philosophy, Pentire Press, London.

2011, A Priori Conjectural Knowledge in Physics, in What Place for the A Priori?,

ed., Michael Shaffer and Michael Veber, Open Court, Chicago, pp. 211-240.

2012a, In Praise of Natural Philosophy: A Revolution for Thought and Life,

Philosophia, vol. 40, no. 4, pp. 705-715.

, 2012b, Arguing for Wisdom in the University: An Intellectual Autobiography,

Philosophia, vol. 40, no. 4, pp. 663-704.

2013, Has Science Established that the Cosmos is Physically Comprehensible?, 
Recent Advances in Cosmology, Travena, A and Soen, B. (eds), Nova Publishers Inc, New York, Chapter One, pp. 1-56.

2014a, How Universities Can Help Create a Wiser World: The Urgent Need for an Academic Revolution, Imprint Academic, Exeter.

,2014b, Global Philosophy: What Philosophy Ought to Be, Imprint Academic, Exeter. 2015, What's Wrong With Aim-Oriented Empiricism?, Acta Baltica Historiae et Philosophiae Scientiarum, vol. 3, no. 2, pp. 5-31.

2016a, Popper's Paradoxical Pursuit of Natural Philosophy, in Cambridge

Companion to Popper, edited by Jeremy Shearmur and Geoffrey Stokes, Cambridge

University Press, Cambridge, ch. 7, pp. 170-207.

2016b, Can Scientific Method Help Us Create a Wiser World?, in N. Dalal, A.

Intezari and M. Heitz, ed., Practical Wisdom in the Age of Technology: Insights,

Issues and Questions for a New Millennium, Routledge, London, ch. 11, pp. 147-

161.

2017a, Understanding Scientific Progress: Aim-Oriented Empiricism, Saint Paul,

Paragon House, Minnesota.

, 2017b, In Praise of Natural Philosophy: A Revolution for Thought and Life,

McGill-Queen's University Press, Montreal.

,2017c, Karl Popper, Science and Enlightenment, UCL Press, London (free to download).

,2018, We Need Progress in Ideas about How to Achieve Progress, Metascience, vol.

27, issue 2, pp. 347-350.

2019a, The Urgent Need for Social Wisdom, In The Cambridge Handbook of

Wisdom, edited by R. Sternberg and J. Glück, ch. 33, 754-80, Cambridge: Cambridge

University Press.

, 2019b, The Metaphysics of Science and Aim-Oriented Empiricism: A Revolution for

Science and Philosophy, Springer, Cham, Switzerland.

, 2019c, Science and Enlightenment: Two Great Problems of Learning, Springer,

Cham, Switzerland.

, 2019d, How Wisdom Can Help Solve Global Problems, in Applying Wisdom to

Contemporary World Problems, edited by R. Sternberg, H. Nusbaum and J. Glück, ch.

13, 337-80, Palgrave Macmillan, London.

2019e, The Scandal of the Irrationality of Academia. Philosophy and Theory in

Higher Education, special issue on "The Anthropocene and Higher Education", 1, issue 1, 105-128.

, 2019f, A New Task for Philosophy of Science, Metaphilosophy, vol. 50, no. 3, pp. 316-338.

,2019g, Natural philosophy redux, Aeon, 13 May 2019.

2019h, The Metaphysics of Science and Aim-Oriented Empiricism, HPS \& ST Note,

May 2019, pp. 13-17.

,2020a, Our Fundamental Problem: A Revolutionary Approach to Philosophy,

McGill-Queen's University Press, Montreal.

2020b, Aim-Oriented Empiricism and the Metaphysics of Science, Philosophia, 48,

pp. 347-364.

Penrose, R., 2004, The Road to Reality, Jonathan Cape, London.

Pinker, S., 2018, Enlightenment NOW: The Case for Reason, Science, Humanism and

Progress, Allen Lane, London.

Polya, G., 1957, How to Solve It. Anchor Books, New York.

Popper, K.R., 1959, The Logic of Scientific Discovery, Hutchinson, London.

Snow, C.P., 1969, The Two Cultures and a Second Look, Cambridge University Press, London. 
${ }^{1}$ Maxwell (2019c).

${ }^{2}$ In more recent times, it goes back to Maxwell (1984; 2000b).

${ }^{3}$ For the $18^{\text {th }}$ century Enlightenment see Gay (1973) and Israel (2013).

${ }^{4}$ For the impact of the Enlightenment on the subsequent development of social science, and academia more generally, see Farganis (1993); Hayek (1979).

${ }^{5}$ For a recent eulogy to the $18^{\text {th }}$ Enlightenment that entirely ignores its three blunders, see Pinker (2018); for a criticism see Maxwell (2018).

${ }^{6}$ For a more detailed exposition of knowledge-inquiry, see Maxwell (1984, ch. 2).

${ }^{7}$ For a more detailed exposition of wisdom-inquiry, see Maxwell (1984, chs. 4 and 5).

${ }^{8}$ Karl Popper alludes to the first two of these rules when he says "the one method of all rational discussion ... is that of stating one's problem clearly and of examining its various proposed solutions critically" Popper (1959, p. 16). Popper was too critical of specialization to advocate the third rule; he failed to appreciate that the bad aspects of specialization can be counteracted by means of the fourth rule. A fifth rule is the one that informs the basic idea of this paper: in seeking to solve a problem, look around for an analogous, already solved problem, and adapt the solution to the new problem you seek to solve. The basic idea of this paper is simply: adapt the solution to the first great problem of learning to help solve the second one. For more about rational problem solving see Maxwell (1984, pp. 67-71); Polya (1957).

${ }^{9}$ For a detailed account of the influence that knowledge-inquiry exercises over academia, see Maxwell (2007, ch. 6).

${ }^{10}$ See Maxwell (2004, pp. 4-7).

${ }^{11}$ The philosophes tended to accept an especially crude, inductivist version of SE that stemmed from Newton. For the impact of Newton on the Enlightenment, see Gay (1973, vol. 2, ch. 3, and ch. 4 , section 2).

${ }^{12}$ I have shown decisively that standard empiricism is untenable and needs to be replaced in very many publications over many years: see Maxwell $(1974 ; 1979 ; 1984$, ch,. 9; 1993; 1997; 1999; 2000a; 2001, app. 3; 2002a; 2002b; 2006; 2009; 2010, ch. 5; 2011; 2012a; 2013; 2014a; 2015; 2016a; 2017b; 2017c; 2019b-h; 2020a; 2020b; and especially 1998, 2004; 2007, ch. 14; 2017a, and 2019b). I give this long list of publications to indicate just how outrageous the intellectual scandal is, that this work has been ignored for so long by the scientific community, and the academic community more generally - work that has profound implications for the nature of science, the nature of academic inquiry more broadly, and for the future of humanity. Specialization has become so endemic and rampant that academia can no longer pick up on work that has major implications for the whole enterprise. This long-standing neglect of my decisive refutation of standard empiricism also highlights, perhaps, just how hard-wired the doctrine is into scientists' brains.

${ }^{13}$ Metaphysical here means untestable.

${ }^{14}$ For details, see Maxwell (2017a, ch. 5). See also Maxwell (1998, chs. 3 and 4; 2004, appendix).

${ }^{15}$ See Maxwell (2017a, especially ch. 9). See also Maxwell (2007, ch. 14; 2013).

${ }^{16}$ See note 12.

${ }^{17}$ See Maxwell (1993, pp. 275-305; 1998, chs. 3, 4 and pp. 220-3; 2017a, ch. 11; 2017b, ch. 5).

${ }^{18}$ For a list of the achievements of AOE see Maxwell (2019b, pp. 106-8).

${ }^{19}$ Throughout we are concerned, not with the aim we declare, or believe we pursue, but our actual aim, that outcome our actions are designed to bring about in our environment.

${ }^{20}$ Our problems are products of our successes.

${ }^{21}$ An elementary argument establishes that reason must include rules for the improvement of aims. In an only partly known world, it is all too likely that our aims will not be in our best interests. In such circumstances, a conception of reason which does not include means for the improvement of aims, will lead us systematically astray. But any conception of reason that leads us systematically astray cannot be authentic reason. Therefore, in order to be authentic, reason must include means for the improvement of aims.

${ }^{22}$ For more detailed expositions of the argument for wisdom-inquiry, see especially Maxwell (1984; $2004 ; 2007 ; 2014 a ; 2017 \mathrm{c} ; 2019 \mathrm{c} ; 2020 \mathrm{a})$. For summaries of the argument see especially Maxwell (1980; 1992; 2000b; 2012b; 2016b; 2018; 2019a; 2019d-e).

${ }^{23}$ Maxwell (1976, p. 5).

${ }^{24}$ Snow (1969).

${ }^{25}$ Einstein (1973, p. 80). 
${ }^{26}$ Einstein (1973, p. 11).

${ }^{27}$ Einstein, 1949, p. 17).

${ }^{28}$ A relatively recent, remarkable exception is Penrose (2004).

${ }^{29} \mathrm{I}$ might add that the hierarchical conception of science indicated here does better justice to the scientific quest for understanding than does orthodox standard empiricist views: see Maxwell (1998, chs. 4 and $8 ; 2004$, ch. 2; 2017b, ch. 5).

${ }^{30}$ These considerations are developed further in Maxwell $(1976 ; 1980 ; 1984 ; 2004 ; 2014 b ; 2017 b$.

${ }^{31}$ For a fuller exposition of such an account of empathic understanding, see Maxwell (1984, pp.

171-189 and ch. 10; and 2001, chs. 5-7 and 9).

${ }^{32}$ See Maxwell (1984, pp. 183-185).

${ }^{33}$ For a list of 23 structural changes that need to be made to transform knowledge-inquiry into wisdom-inquiry, see Maxwell (2014a, pp. 56-60). For more about wisdom-inquiry and its critical reception, see https://www.ucl.ac.uk/from-knowledge-to-wisdom/ . 